\title{
Development and substantiation of main design portable operating table parameters for small animals
}

\author{
Dmitrii Kotov*, Igor Nenashev, Sergei Vdovkin, and Nikolai Kryuchin \\ Samara State Agrarian University, 446442, 2 Uchebnaya, Ust-Kinelskiy, Samara region, Russia
}

\begin{abstract}
The article substantiates the need of development of a portable operating table designed for performing medical manipulations, both in and out veterinary clinics. On the basis of the analysis of existing veterinary operating tables, the design of the portable operating table is proposed the parameters of the main elements are justified by theoretical calculations. The use of the portable operating table due to improvements of its ergonomic characteristics allows reducing the amount of time and improving the quality of operations.
\end{abstract}

\section{Introduction}

The surgical table is an integral part of any operating room in a veterinary clinic. At present, various designs of surgical tables are used in veterinary surgery $[1,2,3,4]$. Their functionality is quite high, and they have a wide range of properties and parameters. However, the majority of produced surgical tables are stationary and they are intended to use only in the veterinary clinics buildings.

One of the most urgent tasks during the medical manipulations, in particular on small animals, is the ability to perform them not only in specialized clinics, but also in nonstationary field conditions, when there is no opportunity or time to transport the animal to a veterinary clinic. A veterinarian must have compact and mobile equipment to provide qualified care at home. In addition, during the simple operations, when the animal does not require constant attention and specialized postoperative care, it remains in the familiar home environment reducing stress.

Thus, it is necessary to develop a portable operating table that allows you to perform medical manipulations not only in but out veterinary clinics, at the patient's home.

Special demands on operating tables are made, since their design must ensure the performance of complex and time-consuming therapeutic and surgical manipulations. Operating tables should be easy to assemble and to operate they should be reliable and convenient, as well as they should fix the animal in the desired position qualitatively.

In this regard, one of the most promising directions should be considered to be the development, design, manufacture and implementation of mobile portable operating tables

\footnotetext{
${ }^{*}$ Corresponding author: Kotov DN@ssaa.ru
} 
which allow you to mount a table quickly in the field conditions and perform an operation with high quality.

As a result of the analysis of operating tables used at present, it was found that most of them are stationary, do not have portability even in the operating room, have relatively large dimensions and weight, do not provide the possibility of table transporting for medical visits, for example, to agricultural farms. Most of operating tables, including portable ones, do not have a constructive ability to adjust the height of the lift and the angle of the table top inclination, which reduces the convenience and efficiency of dogs and cats surgical interventions in during herniotomy and operations on the internal organs of the abdominal cavity. Large dimensions and weight of portable tables even folded ones create inconveniences during transportation.

In this regard, scientists of the Samara state agrarian university have developed the design of a portable operating table, the design features of which are protected by Russian Federation patent №182744 [5].

\section{Design diagram of portable operating table}

When designing the operating table the following design parameters were taken: height of the table in lower limit position - max $90 \mathrm{~cm}$; in upper limit position - min $120 \mathrm{~cm}$; panel length of the table top - min $110 \mathrm{~cm}$; panel width - $\min 50 \mathrm{~cm}$. The side tilt angle of the panel to both sides - min 30 degrees; the longitudinal tilt angle of the panel to both sides min 20 degrees. Approximate weight of the portable operating table is no more than $15 \mathrm{~kg}$. When folded, the table top and the rack are folded separately, while the table top is folded to a size of no more than $55 \times 50 \times 10 \mathrm{~cm}$.

The portable operating table (Fig. 1) contains a table top 3 connected to a vertical rack 1 by means of a spherical joint 2, a table top 3 is made from front 4 and back 5 halves, connected pivotally by side loops 6 and 7 .

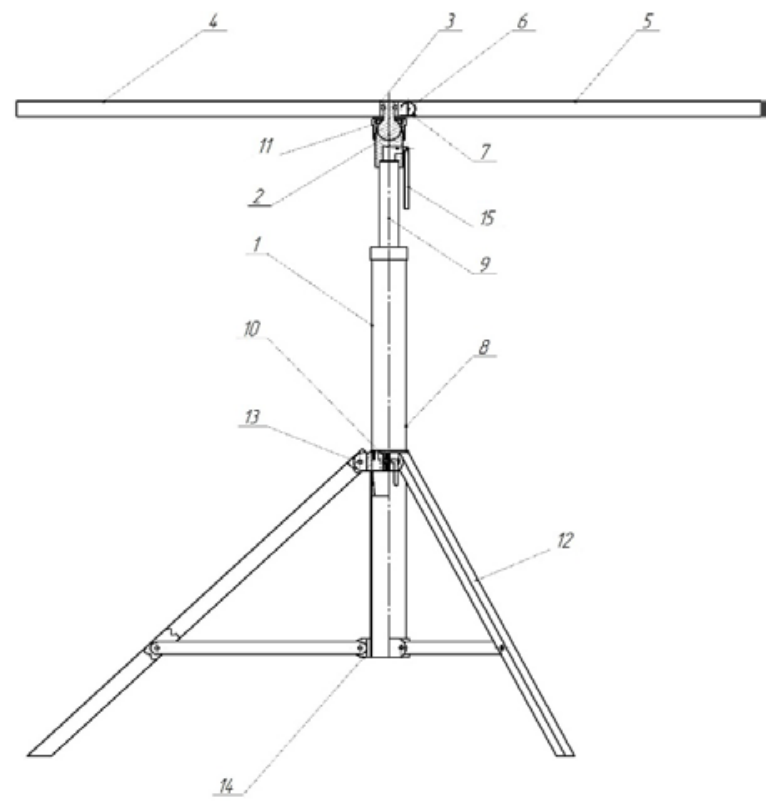

Fig. 1. Design diagram of a portable operating table. 
The vertical rack 1 is made of two-section telescopic, while a standard product - a pneumatic cartridge 9 are used as the second upper section, coaxially installed in the lower section 8 of the rack 1 .

In this case, the lower section 8 is provided with a fixing device 10 of collet type for forced fixation of the telescopic connection.

Thus, the height of the table top lift 3 can be adjusted by using a two-section telescopic rack 1 and a pneumatic cartridge 9 , and you can also change the angle of the table top by fixing the spherical joint 2 with a clip 11.

On the lower section 8 of the vertical rack 1, three support legs 12 are pivotally fixed, connected to the lower section 8 by means of the upper nut 13 (fixed) and the lower nut 14 - movable.

The portable operating table works as follows.

If for the convenience of operating actions the height of the table working position should be changed, for example to raise the table up, you must pull the l-shaped lever 15, mounted in the housing of the spherical joint 2, which presses the button of the pneumatic cartridge rod 9, and the table top rises. When the lever 15 is released, the button closes, respectively, the cartridge rod 9 stops in a certain position.

If for convenience you want to tilt the table top 3, the clamp 11is weakened, the spherical joint 2 provides the table top 3 tilt at the same time along three parallel axes, it improves the usability of the table.

To move the table to a transportable position: the table top 2 and the vertical rack 1are separated, the support legs 12 are folded, and the table top 3 and rack 1 are placed in the covers separately.

The portable operating table is made of durable material that is resistant to mechanical corrosion, while the table surface is made of stainless steel.

The design of the portable operating table must meet the structural requirements for strength and stability.

\section{Substantiation of the main design portable operating table parameters for small animals}

In order to improve the reliability of the structure and ensure its workability, calculations were made for the stability of the structure and the strength of the main structural elements.

According to the design specifications for the development of the declared portable operating table, the maximum load is $350 \mathrm{H}$, which corresponds to the animal weight of 35 $\mathrm{kg}$.

To calculate the stability, we will take the most unfavourable variant of load placement. Apply force $\mathrm{F}=350 \mathrm{H}$ to the angle at point $\mathrm{A}$ of the table top (Fig. 2). Table weight or gravity for preliminary calculations according to the design specifications, we accept $G=$ $150 \mathrm{H}$ or $15 \mathrm{~kg}$. The point of gravity application is the central point of the table top, which coincides with the place of attachment of a supporting rack with a tripod. To ensure the stability of the surgical table at assumed load, the following conditions must be met:

$$
G \times O A=F \times A B
$$

It follows

$$
\frac{F}{G}=\frac{O A}{A B}
$$



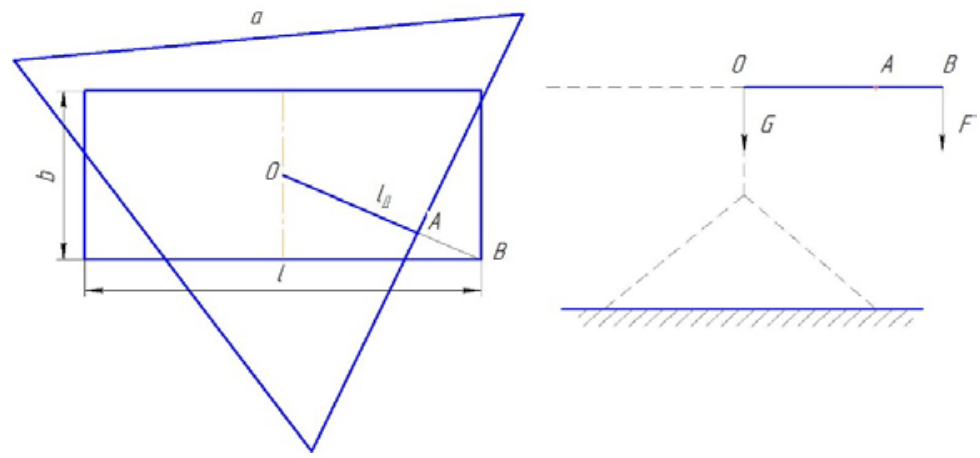

Fig. 2. A diagram of load application.

The diagonal distance from the center to the point of force application basing on the given table top dimensions will be $O B=l_{L}=0,6 \mathrm{~m}$.

As a result of solving equation (2), the minimum size of OA was determined, at which the condition of equilibrium of the loaded table is satisfied.

The value $\mathrm{OA}=0,41 \mathrm{~m}$ is a radius $r$ of a circle inscribed in an equilateral triangle. To determine the projection of the length of the rack, we found the radius of the circle circumscribed around a triangle, which was $\mathrm{R}=0,82 \mathrm{~m}$.

The obtained value of the projection of the rack length is necessary to ensure the stability of the surgical table with a maximum load of $35 \mathrm{~kg}$ applied to the corner of the table. However, it is not rational to perform tripod supports of such length because of their large dimensions and reduced ergonomic characteristics of the table using. As a rule, during operations, the animal is located in the center of the table, and small animals can be located on a half of the table for surgeon convenience, and the other half is occupied with tools used in the operation (Fig. 3).

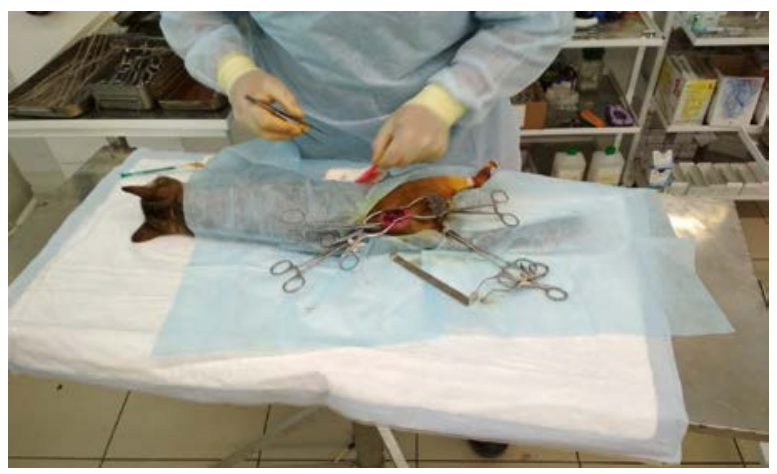

Fig. 3. Example of an animal placement on a portable operating table.

In this regard, the recalculation of the supporting legs size was carried out on the basis of the calculated load q applied uniformly to half surface area of the table (Fig. 4).

In the calculations, the load q evenly distributed over the table top area was replaced by concentrated force $\mathrm{F}=350 \mathrm{H}$ acting in the center of the table top half.

As a result of calculations, the minimum size of the support projection on the horizontal plane to ensure the stability of the portable operating table at the maximum load in the central point of the table top half should be at least $0,39 \mathrm{~m}$.

During the design of the support table part, it is possible to increase the size of this projection. It will help to increase the stability of the entire structure. When choosing the 
final size of the support part, we were also guided by the convenience of work and the location of the support legs in relation to the surgeon's position.

For preliminary calculations, the value of the horizontal support leg projection was assumed to be $500 \mathrm{~mm}$.

To determine the structural dimensions of the ball bearing, telescopic elements of the rack, supporting legs and rails, normal and transverse forces, as well as bending moments were calculated (Fig. 4).
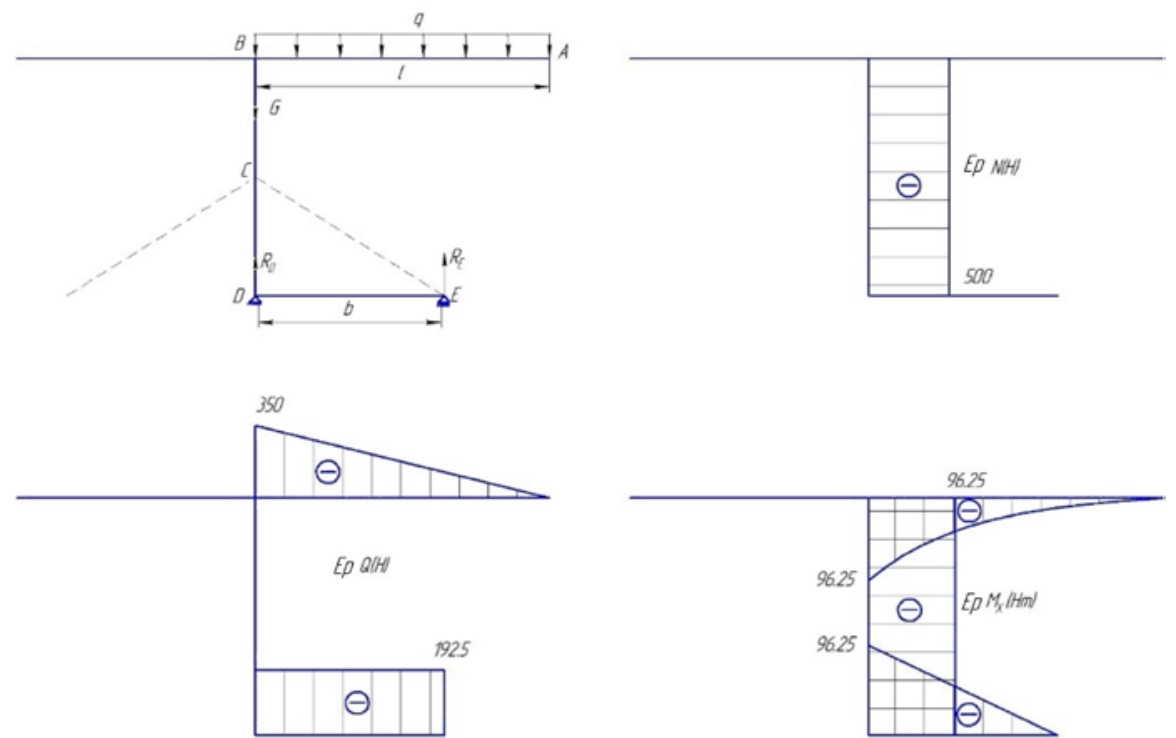

Fig. 4. A diagram and a load diagram of a portable operating table

The minimum diameter of the spherical joint rod was determined based on the bending strength condition [6]:

$$
\sigma=\frac{M_{x}}{W_{x}} \leq[\sigma],
$$

where $\mathrm{M}_{\mathrm{x}}$ - frame bending moment where the table top spherical joint is installed., Hm;

$\mathrm{W}_{\mathrm{x}}$ - axial moment of resistance of the cross section of the spherical joint rod, $\mathrm{cm} 3$;.

$[\sigma]$ - allowable stress of the material of which the spherical joint is made, Pa; for duralumin $[\sigma]=100 \mathrm{MPa}[7]$.

Taking into account the axial moment of resistance of the circular cross section of the spherical joint rod $\mathrm{W}_{\mathrm{x}}$ :

$$
W_{x}=\frac{\pi d^{3}}{32},
$$

where $\mathrm{d}$ - is the diameter of the spherical joint rod, mm.

minimum diameter of the spherical joint rod is:

$$
d=\sqrt[3]{\frac{32 W_{x}}{\pi}}=\sqrt[3]{\frac{32 \cdot 0,9625 \cdot 10^{-6}}{3,14}}=0,021 \mathrm{~m}
$$

Thus, to ensure strength, a spherical joint made of duralumin must have a rod diameter of $\min 21 \mathrm{~mm}$. The size deviation $\delta= \pm 5 \%$ is allowed. 
The required tightening torque of the ball joint nut, which should provide the friction moment $\mathrm{M}_{\mathrm{Fr}}$ to hold the tabletop in the working position, is determined from the expression:

$$
M_{F r}=f^{\prime} \cdot Q \cdot r
$$

where f' - the coefficient of friction in the rotational pair;

$\mathrm{Q}$ - resulting load on the pin, $\mathrm{H}$;

$\mathrm{R}$ - radius of the joint, $\mathrm{m}$.

The coefficient of friction f' is determined experimentally for various working conditions of rotational pairs and it is varied significantly depending on the material and the state of the rubbing surfaces, their working conditions, etc. For unrun joints with dry friction, $\mathrm{f}$ ' is usually assumed to be equal [7]:

$$
f^{\prime}=\frac{3}{2} f,
$$

where $\mathrm{f}$ - coefficient of friction of flat touching surfaces made of the same material.

The value of the coefficient of friction for aluminium $\mathrm{f}=1.05 \ldots 1.35$.

The axial tightening force of the ball joint nut must be at least:

$$
Q=\frac{M_{F r}}{\frac{2}{3} r \cdot f}=\frac{35,3}{\frac{2}{3} \cdot 0,03 \cdot 1,2}=1472 \mathrm{H}
$$

The calculated internal diameter of the thread providing force tightening is determined by the expression [7]:

$$
d_{1} \geq \sqrt{\frac{4 \cdot F_{p}}{\pi[\sigma]}}
$$

where Fp - the calculated force in the bolt shaft, $\mathrm{H}$;

[б] - permissible tensile stress of the material for threaded parts, [ $\left.\sigma_{\mathrm{cm}}\right]=160 \mathrm{MPa}$ [7].

According to the results of the calculation, the diameter of the spherical joint was assumed to be $\mathrm{d}=50 \mathrm{~mm}$.

Thus, to ensure the strength of the table support, it is necessary to use a pipe with an external diameter of at least $30 \mathrm{~mm}$.

To fulfil the design documentation, the guide rails cross-sections of the telescopic rack, the tripod support in the form of a U-shaped profile and its extensions were calculated and selected.

\section{Results and discussion}

The made calculations allow us to determine the design dimensions of the main components and parts of the portable operating table prototype and perform working drawings of the parts and components which were used to manufacture the prototype.

The portable operating table was used for veterinary operations and manipulations. Testing of the prototype was carried out on the basis of veterinary clinics of Samara and Ulyanovsk regions. A comparative analysis of the main surgical and therapeutic procedures performed on the developed portable table and Vinogradov's table showed that $94 \%$ of the working time are used effectively when veterinary specialists apply the portable tables in their daily work in veterinary clinics, the employment level of operational work performers 
was $81 \%$, and there are some reserves for improving efficiency of labour by eliminating irregular breaks by $4.9 \%$. [8].

The article is based on the results of the research and development works entitled "Development and prototype production of a portable operating table for small animals" (Project № 35334, application C1-26852 for the purpose of project implementation "Portable veterinary operational surgical complex"), with grant support of Foundation for Assistance to Small Innovative Enterprises in Science and Technology (Innovation Promotion Foundation) in 2017-2018.

\section{References}

1. L. P. Petrenko, Medical surgical table robototekhnike-tion system, Patent No. 2464004 Russian Federation, publ. 10.05.2012, byul. No. 13

2. Veterinary table Vinogradov "Practitioner" [Electronic resource]. - URL: https://tiu.ru/p21189356-veterinarnyj-stol-vinogradova;all.html - Title from screen.

3. Table COY1 operating a universal motor driven [Electronic resource]. - URL:

http://www.mediform.ru/print/stol-sou-1-operatsionnyj-universalnyj-s-motornymprivodom - Title from screen.

4. I. V. Nenashev, M. S. Seitov, A. O. Lobanova, Operating table for small animals, Patent No. 2565736 Russian Federation, publ. 20.10.2015, byul. No 29.

5. I. V. Nenashev, S. V. Vdovkin, D. A. Konyshev, D. N. Kotov, Portable operating table for small animals, Patent No. 182744 Russian Federation, publ. 29.08.2018, byul. No. 25.

6. V. L. Nikolaenko, Applied mechanics. Calculation of typical structural elements (Minsk, Publishing house Grevtsova, 2010).

7. G. S. Pisarenko, Handbook of resistance to materials (Kiev, Naukova Dumka, 1988).

8. I. V. Nenashev, D. N. Kotov, S. V. Vdovkin, E. M. Marin, V. A. Ermolaev, and O. N. Marina, Testing Of Portable Surgical Table In The Treatment Of Small Animals (SOP1), Research Journal of Pharmaceutical, Biological and Chemical Sciences; 10(2). 4149. (2019). 